\title{
PRAKTEK MANAJEMEN INOVASI DI S1 MANAJEMEN BISNIS FAKULTAS EKONOMI UNIVERSITAS TARUMANAGARA
}

\author{
Richard Andrew ${ }^{1}$, Verena Sandra Esmeralda ${ }^{2}$, Roy Willis ${ }^{3}$ dan Angelica Sunjaya ${ }^{4}$ \\ ${ }^{1}$ Jurusan Manajemen Bisnis, Universitas Tarumanagara Jakarta \\ richarda@fe.untar.ac.id \\ 2 Jurusan Manajemen Bisnis, Universitas Tarumanagara Jakarta \\ verena.115150049@stu.untar.ac.id \\ ${ }^{3}$ Jurusan Manajemen Bisnis, Universitas Tarumanagara Jakarta \\ roy.115150431@stu.untar.ac.id \\ ${ }^{4}$ Jurusan Manajemen Bisnis, Universitas Tarumanagara Jakarta \\ angelica.115150009@stu.untar.ac.id
}

\begin{abstract}
ABSTRAK
Inovasi yang berkelanjutan di universitas seperti pada di berbagai macam jenis institusi lain di bidang pendidikan tinggi mutlak harus dilakukan agar tetap dapat bertahan dalam kerasnya persaingan di dunia pendidikan tinggi. Akan tetapi, hanya sedikit pimpinan perguruan tinggi yang memiliki kesadaran untuk senantiasa berinovasi. Oleh sebab itu, tim penulis melakukan penelitian secara intensif untuk mendeskripsikan berbagai inovasi yang telah diterapkan dan akan dilakukan oleh jurusan Manajemen Bisnis, Fakultas Ekonomi di Universitas Tarumanagara. Adapun metode yang digunakan dalam riset ini adalah menggunakan metode kualitatif dengan menggunakan pertanyaan wawancara semi terstruktur kepada pimpinan jurusan Manajemen Bisnis. Hasil penelitian ini mengungkapkan bahwa strategi inovasi yang digunakan sudah berjalan dengan baik dan senantiasa berkembang sesuai dengan perkembangan zaman. Namun, untuk mendapatkan hasil ini tentunya tidak mudah dan banyak kendala yang harus diatasi satu per satu. Tentunya inovasi ini masih perlu pembenahan ke depan agar dapat bersaing tidak hanya di tingkat nasional tetapi juga di tingkat global khususnya di kawasan Asia Tenggara sesuai dengan visi Universitas Tarumanagara itu sendiri. Hasil ini kemudian dapat dijadikan acuan untuk jurusan S1 Manajemen Bisnis di perguruan tinggi lain untuk berkembang sesuai dengan harapan dari Kementrian Riset dan Pendidikan Tinggi Republik Indonesia. Dari penelitian ini, tim penulis dapat mengambil kesimpulan bahwa praktek manajemen inovasi juga ada di jurusan S1 Manajemen Bisnis Universitas Tarumanagara.
\end{abstract}

Kata kunci: Manajemen, Inovasi dan Pendidikan Tinggi

\section{PENDAHULUAN}

Banyak institusi yang bergerak pada sektor jasa masih belum menyadari pentingnya melakukan inovasi secara berkelanjutan. Padahal inovasi merupakan salah satu elemen penting dalam menjaga keberlangsungan dari institusi tersebut. Adapun inovasi di bidang jasa seperti yang dituturkan oleh Droege, Hildebrand dan Forcada (2009) telah didiskusikan sejak tahun 1980an. Penelitian terdahulu memperlihatkan bahwa inovasi di bidang jasa harus dikelola dengan cara berbeda dari inovasi pada barang. Hal ini terutama yang berkaitan dengan proses inovasi (Gallouj dan Weinstein: 1997), kapabilitas yang dibutuhkan (Den Hertog, Van Der Aa dan De Jong: 2010), kompleksitas organisasi (Johne dan Storey: 1998) dan sebab akibat (Aas dan Pedersen: 2010).

Hasil yang bervariasi pada sektor jasa ini disimpulkan oleh Zomerdijk dan Voss (2010) sebagai suatu eksistensi akan perbedaan antara pengembangan jasa dan barang serta perbedaan antara suatu jasa dengan tipe jasa yang lain. Ada beberapa penelitian terdahulu untuk mempelajari mengenai pentingnya inovasi pada zaman ini, dari penerapannya dalam kegiatan bisnis sampai institusi pendidikan sekalipun. Howells, Ramlogan, dan Cheng (2012) telah menyelidiki peran penting dari inovasi dan pertumbuhan pada perguruan tinggi lain yang menerapkan sistem inovasi terbuka dengan korporat ternama di Inggris. 
Senada dengan hal tersebut, Perkmann dan Walsh (2007) menyatakan bahwa inovasi terbuka penting untuk menciptakan inovasi pada sektor pelayanan dan transfer teknologi melalui riset kolaboratif dan hubungan yang positif. Secara lebih spesifik lagi, White dan Glickman (2007) mengungkapkan bahwa ada banyak praktek inovasi yang dilakukan kampus seperti inovasi di bidang kurikulum yang dilakukan oleh Western Governors University dan Leadership Foundation untuk perguruan tinggi.

Berdasarkan hal tersebut maka tim peneliti menentukan tujuan utama dari penelitian ini yakni untuk menambah pengetahuan seputar praktek manajemen inovasi pada perguruan tinggi khususnya Jurusan S1 Manajemen Bisnis Fakultas Ekonomi Universitas Tarumanagara. Adapun 2 pertanyaan kunci pada penelitian ini adalah sebagai berikut:

P1: Apa saja praktek manajemen inovasi pada jurusan S1 Manajemen Bisnis Fakultas Ekonomi Universitas Tarumanagara?

P2: Bagaimana perbedaan praktek tersebut dengan praktek manajemen inovasi di bidang industri lain?

\section{METODE PENELITIAN}

Untuk menguji praktek manajemen inovasi di bidang jasa dan untuk mendapatkan pemahaman yang lebih mendalam, tim peneliti menggunakan pendekatan kualitatif untuk studi kasus ini seperti yang digunakan oleh Yin (2003). Sebuah penelitian kualitatif, bisa dibilang memiliki keunggulan ketika fenomena yang akan diteliti tidak dipahami dengan baik dan variabel masih belum diketahui (Johnson dan Harris: 2003). Dengan demikian, pendekatan kualitatif juga memungkinkan pendalaman tentang praktek inovasi dibanding dengan metode penelitian kuantitatif.

Sugiyono (2005) mengungkapkan bahwa penelitian kualitatif adalah penelitian yang digunakan untuk meneliti pada kondisi objek alamiah dimana peneliti merupakan instrumen kunci sehingga isi dari riset bersifat deskriptif dan cenderung menggunakan analisis. Dari penjelasan tersebut tim peneliti kemudian menggunakan metode kualitatif untuk studi kasus ini untuk mendeskripsikan berbagai inovasi yang telah diterapkan dan akan dilakukan oleh jurusan S1 Manajemen Bisnis, Fakultas Ekonomi, Universitas Tarumanagara. Adapun sumber data yang digunakan dalam riset ini terdiri dari data primer yang berasal dari wawancara, observasi dan diskusi serta data sekunder yang berasal dari studi literatur dan informasi lain.

Untuk data primer, tim penulis membentuk panduan wawancara semi terstruktur yang mencerminkan praktek manajemen inovasi. Panduan ini berisi tentang strategi, budaya organisasi, inovasi, portfolio dari manajemen, proses pengembangan, fasilitas dan metode serta langkah intelektual lain yang ada dalam sumber daya organisasi. Agar terperinci maka informan pada penelitian ini menyebutkan dua inisiatif inovasi yang telah dilakukan sehingga tim peneliti dapat menilai tingkat keterlibatan informan dalam implementasi inovasi tersebut. Hal ini penting dalam penelitian terutama karena informan pasti percaya praktek inovasi tersebut sukses.

Kegiatan wawancara dilakukan oleh tim peneliti kepada pimpinan jurusan Manajemen Bisnis, Fakultas Ekonomi di Universitas Tarumanagara. Wawancara tersebut dibuat transkrip yang kemudian dikodekan dan dipetakan ke dimensi manajemen inovasi (strategi dan budaya, ujung depan inovasi dan manajemen portofolio, proses pembangunan, intelektual dan sumber daya organisasi). Untuk memastikan validitas informasi mengenai inovasi jasa, proses pengodean dan pemetaan dilakukan dengan sumber lain juga dalam hal ini opini dari Dekan Fakultas Ekonomi dan beberapa civitas akademika S1 Manajemen Bisnis lain. Setelah itu, hasil dibahas antara 
peneliti sampai konsensus umum dicapai. Akhirnya, data dikodekan dianalisis dan dibandingkan untuk mendapatkan hasil yang akurat.

\section{HASIL DAN PEMBAHASAN}

Tiap institusi pasti memiliki tujuan bisnis strategisnya masing-masing, dan tak jarang yang menyebutkan inovasi sebagai salah satu instrumen taktis untuk menjembatani situasi perusahaan saat ini dengan ambisi yang hendak mereka capai. Hal yang sama juga terjadi di S1 Manajemen Bisnis Fakultas Ekonomi Universitas Tarumanagara. Sebagai seseorang yang harus bisa meningkatkan peringkat S1 Manajemen Bisnis untuk bisa sejajar dengan program studi serupa dari Perguruan Tinggi Negeri maupun Swasta, pimpinan jurusan S1 Manajemen Fakultas Ekonomi Universitas Tarumanagara mengatakan banyak inovasi yang telah dan akan dilakukan. Dua diantaranya adalah peningkatan kualitas laboratorium dan program kelas unggulan.

Berbicara soal proses, ide inovasi bisa datang dari berbagai sumber. Bisa berasal dari pesaing, karyawan, pemerintah dan masih banyak sumber lain. Di S1 Manajemen Bisnis Fakultas Ekonomi Universitas Tarumanagara itu sendiri, sumber ide umumnya datang dari hasil diskusi, "(...) didahului proses diskusi dari dosen dan wakil mahasiswa." Menurut pimpinan jurusan S1 Manajemen Fakultas Ekonomi Universitas Tarumanagara, ada hubungan antara strategi dan inovasi, seperti yang dikatakan: "Jika dosen-dosen dan para kepala lab sudah mengerti tolak ukur dan keberhasilan di tempat lain, maka proses inovasi akan terjadi. Mereka akan tahu hal positif apa saja yang dapat digunakan sebagai faktor penciptanya nilai tambah di Fakultas Ekonomi Universitas Tarumanagara."

Hal ini selaras dengan pernyataan Carnegie dan Butlin (1993) yang mendefinisikan inovasi sebagai "sesuatu yang baru atau ditingkatkan yang dihasilkan oleh perusahaan guna menciptakan nilai tambah yang signifikan baik secara langsung atau tidak langsung yang memberi manfaat kepada perusahaan dan atau pelanggannya". Namun di lain sisi, ide-ide besar butuh dana yang tidak sedikit untuk merealisasikannya. "Pengalaman pada saat membuat galeri investasi sebagai bentuk fisik nyata laboratorium pasar modal, butuh dana yang luar biasa. Sedikitnya butuh 2 mitra, Bursa Efek Indonesia dan satu perusahaan sekuritas terpilih PT Sucorinvest Asset Management. Besaran investasi kira-kira mendekati Rp100.000.000,-". Oleh sebab itu dalam tahap pengembangan harus dipertimbangkan dengan baik.

Untuk melaksanakan kegiatan inovasi, perusahaan memerlukan sumber daya-sumber daya, seperti sumber daya intelektual, sumber daya organisasi, dan sumber daya fisik. Tenaga kerja adalah asset utama perusahaan yang menjadi perencana dan juga pelaku aktif dari setiap aktivitas dalam organisasi. Dalam merekrut tenaga kerja baru di S1 Manajemen Bisnis Fakultas Ekonomi. Salah satu kriteria penting untuk calon dosen adalah berprestasi akademik baik, memiliki pengalaman mengajar serta memiliki kemampuan berjejaring. Tentu setelah direkrut akan senantiasa dievaluasi dengan dibantu 2 sekretaris jurusan. "Yang satu tugasnya untuk mempersiapkan, merencanakan, dan mengembangkan sisi akademik. Yang lainnya untuk non akademik, seperti pengembangan dosen dan karyawan di jurusan sebagai sumber daya-sumber daya penting (kompetensi, renumerasi, dll)."

Selain kepala jurusan dan beberapa staf, ada tenaga administrasi yang menjalankan kegiatan operasional agar selalu tertib proses perkuliahan, ujian dan registrasi tiap semester beserta Kepala Laboratorium dengan dibantu oleh satuan petugas pelaksana yang membantu aktivitas laboratorium, perkulihan serta surat menyurat masuk keluar. Di S1 Manajemen Bisnis Fakultas Ekonomi Universitas Tarumanagara, dalam hal inovasi pembelajaran, sudah dikembangkan dan diterapkan Google Classroom. Untuk di masa mendatang, Dekan Fakultas Ekonomi beserta 
dengan Ketua Jurusan S1 Manajemen Bisnis berharap mampu mengimplementasikan pelaksanaan absensi secara digital disertai dengan perkuliahan berbasis online jarak jauh. Akan tetapi, hal ini dijelaskan pimpinan jurusan masih butuh proses panjang karena "... masih terbentur aturan main UNTAR".

Terkait pelaksanaan inovasi, seperti pada organisasi lain, tentu akan ada masalah yang harus dihadapi, karena masalah merupakan sesuatu yang alami. Tak terkecuali jurusan S1 Manajemen Bisnis Fakultas Ekonomi Universitas Tarumanagara, namun masalah yang dihadapi tidak signifikan. "Sl Manajemen Bisnis tidak ada konflik yang signifikan. Yang terjadi hanya perbedaan persepsi antara dosen dan umumnya sudah bisa diselesaikan di rapat koordinasi, soalnya UNTAR menganut azas kekeluargaan. Umumnya masalah perbedaan adalah dalam beban tugas, skala prioritas, dan bentuk insentif khusus. Biasanya selesai ketika saya, temanteman dosen, duduk bareng bersama dekanat untuk membicarakan solusi yang tepat."

Setelah dilaksanakan, perlu adanya pengukuran hasil inovasi, karena pengukuran adalah langkah pertama dalam perbaikan. Tolak ukur untuk keberhasilan tiap-tiap inovasi di S1 Manajemen Bisnis Fakultas Ekonomi Universitas Tarumanagara berbeda-beda. Untuk laboratorium pengukuran inovasi dilakukan dengan adanya perkembangan yang baik dimulai dari konsentrasi pemasaran setelah hadirnya laboratorium penelitian pemasaran. Selain itu laboratorium juga secara konsisten menyelenggarakan seminar yang dibawakan oleh pakar investasi berskala nasional secara berkelanjutan. Ini sejalan tentunya dengan pergerakan kerjasama dengan beberapa organisasi di luar UNTAR seperti AMA, ALFED dan FMI.

Untuk inovasi pada kelas unggulan, tahun lalu telah sukses dijalankan oleh 10 instruktur pada 10 program pelatihan berbeda. Lebih jauh lagi inovasi ini terbukti membantu jurusan meraih beberapa prestasi pada kompetisi nasional baik pada nomor tim maupun pada nomor perseorangan. Tentunya inovasi ini telah dibuatkan laporan pertanggungjawaban yang disusun dengan seksama. Jurusan juga melaksanakan beberapa masukan dari mahasiswa yang menginginkan adanya program kelas paket seperti yang sudah diterapkan di S1 Akuntansi. "Guna mengakomodasi permintaan, maka saya sudah memutuskan untuk berikan dengan pemantauan mulai minggu ke-2. Kekurangan 3 dosen sudah dijajaki dan akan mulai bergerak minggu ke-3 di bulan Februari. Mahasiswa juga harus komitmen untuk berpartisipasi."

Selanjutnya, agar pelatihan tetap inovatif, semester genap akan dibawakan lebih kearah soft skill seperti English proficiency dan table manner.

Dari hasil pengukuran tersebut, pimpinan jurusan S1 Manajemen Bisnis Fakultas Ekonomi Universitas Tarumanagara menyatakan bahwa ada beberapa inovasi layanan yang sudah dilakukan dengan baik, tapi ada beberapa yang masih memerlukan perbaikan. Yang sudah dilakukan dengan baik adalah menempatkan beberapa pengumuman akademik yang sangat vital untuk mahasiswa yaitu jadwal perkuliahan, BPMK, jadwal ujian, kurikulum, tanggal-tanggal penting, daftar ujian nama-nama dosen pembimbing skripsi, dosen Penasehat Akademik, koordinator di website FE UNTAR dan di jurusan. Sedangkan yang masih perlu perbaikan adalah percepatan informasi kegiatan jurusan S1 Manajemen Bisnis melalui layar digital dan prosedur tatap muka dengan orangtua mahasiswa dan tamu penting program studi lainnya.

\section{KESIMPULAN DAN SARAN}

S1 Manajemen Bisnis Fakultas Ekonomi Universitas Tarumanagara sudah melakukan berbagai inovasi sebagai praktek nyata agar bisa sejajar dengan program studi serupa di perguruan tinggi lain baik negeri maupun swasta. Praktek inovasi tersebut diantaranya adalah inovasi pada Laboratorium dan Program Kelas Unggulan. Praktek inovasi pada laboratorium mencakup beberapa hal yakni pengadaan galeri investasi pada laboratorium pasar modal, pengembangan 
laboratorium riset pemasaran melalui laboratorium manajemen kuantitatif dan peningkatan penggunaan aplikasi teknologi informasi termutakhir pada laboratorium aplikasi komputer. Untuk inovasi di program kelas unggulan mencakup program kelas paket dan program pelatihan yang bervariasi yang telah berhasil menghasilkan juara kompetisi tingkat nasional serta lulusan yang mampu bersaing di dunia kerja.

Adapun yang membedakan praktek manajemen inovasi di S1 Manajemen Bisnis Fakultas Ekonomi Universitas Tarumanagara dengan program studi sejenis di perguruan tinggi lain adalah sumber inovasi itu sendiri. Di S1 Manajemen Bisnis Fakultas Ekonomi Universitas Tarumanagara, setiap inovasi adalah hasil diskusi antara jurusan dengan perwakilan Dosen baik yunior maupun senior dengan perwakilan mahasiswa. Di samping itu justru hambatan inovasi ada dalam proses pengambilan keputusan yang cukup panjang dengan aturan yang relatif terlalu ketat sehingga beberapa inovasi masih dalam proses seperti absensi digital untuk memudahkan penertiban proses kegiatan pembelajaran di kelas, penambahan fasilitas pada jurusan seperti layar digital dan sistem perkuliahan jarak jauh.

Di masa mendatang, tim peneliti berharap agar proses inovasi tidak terhambat, S1 Manajemen Bisnis Fakultas Ekonomi Universitas Tarumanagara mendapatkan calon mitra untuk pemenuhan kebutuhan dana dari luar tanpa dibatasi aturan yang menghambat inovasi serta percepatan proses digitalisasi pada universitas itu sendiri. Untuk penelitian lebih lanjut, peneliti menyarankan penambahan pihak yang diwawancara dengan dilaksanakannya studi banding ke program studi sejenis di perguruan tinggi lain.

\section{Ucapan Terima Kasih (Acknowledgement)}

Tim Penulis mengucapkan banyak terima kasih kepada semua pihak yang telah membantu proses penerbitan hasil penelitian ini khususnya kepada Ketua Jurusan S1 Manajemen Bisnis Dr. Ignatius Roni Setyawan, M.Si. selaku nara sumber utama, Dekan Fakultas Ekonomi Universitas Tarumanagara Dr. Sawidji Widoatmodjo, M.M., M.B.A. selaku pihak yang selalu mendukung kemajuan riset di Fakultas dan Prof. Dr. Agustinus Purna Irawan, S.T., M.T. selaku Rektor Universitas Tarumanagara.

\section{REFERENSI}

Aas, T. H. \& Pedersen, P. E. (2010). The firm-level effects of service innovation: A literature review. International Journal of Innovation Management, 14(5), 759-794.

Carnegie, R. \& Butlin, M. (1993). Managing the Innovating Enterprise: Australian Companies Competing with World's Best. Business Council of Australia, Melbourne.

Den Hertog, P., Gallouj, F \& Segers, J. (2011). Measuring innovation in a 'low-tech' service industry: the case of the Dutch hospitality industry. Service Industries Journal, 31(9), 1429-1449.

Droege, H., Hildebrand, D. \& Forcada, M. A. H. (2009). Innovation in services: present findings, and future pathways. Journal of Service Management, 20(2), 131-55.

Gallouj, F. \& Weinstein, O. (1997). Innovation in services. Research Policy, 26, 537-556.

Gloet, M., \& Terziovski, M. (2004). Exploring the relationship between knowledge management practices and innovation performance. Journal of Manufacturing Technology Management, 15(5), 402-409.

Howells, J., Ramlogan, R., \& Cheng, S. L. (2012). Innovation and university collaboration: paradox and complexity within the knowledge economy. Cambridge Journal of Economics, 36(3), 703-721. 
Johnson, P. \& Harris, D. (2003). Qualitative and Quantitative Issues in Research Design. Sage Publications, London.

Perkmann, M. \& Walsh, K. (2007). University-industry relationships and open innovation: Towards a research agenda. International Journal of Management Reviews, 9(4), 259-280.

Sugiyono, M. P. A., (2005). Metode Penelitian Kuantitatif, Kualitatif dan R\&D. Alfabeta, Bandung.

White, S. C., \& Glickman, T. S. (2007). Innovation in higher education: Implications for the future. New Directions for Higher Education, 137, 97-105.

Yin, R. K. (2003). Case Study Research-Design and Methods 3rd ed of Thousand Oaks. Sage Publications, London.

Zomerdijk, L. G. \& Voss, C. A. (2011). NSD Processes and Practices in Experiential Services. Journal of Product Innovation Management, 28, 63-80. 